\title{
Cocaine Self-Administration Reduces Excitatory Responses in the Mouse Nucleus Accumbens Shell
}

\author{
Nicole L Schramm-Sapyta ${ }^{1,4}$, Christopher M Olsen ${ }^{1,2}$ and Danny G Winder*, , 2,3 \\ 'Department of Molecular Physiology \& Biophysics, Vanderbilt University School of Medicine, Nashville, TN, USA; ${ }^{2}$ Center for Molecular \\ Neuroscience, Vanderbilt University School of Medicine, Nashville, TN, USA; ${ }^{3} J$ F Kennedy Center for Research on Human Development, \\ Vanderbilt University School of Medicine, Nashville, TN, USA
}

\begin{abstract}
Drugs of abuse affect behavior by altering neuronal communication within the brain. Previous research examining the effects of intraperitoneally administered cocaine has revealed that cocaine alters excitatory glutamatergic signaling, both directly through regulation of synaptic function, and indirectly through regulation of cellular excitability in areas of the drug reward circuitry such as the nucleus accumbens (NAcc) and ventral tegmental area. We have now extended these findings by testing the hypothesis that self-administration of cocaine might elicit similar alterations in excitatory signaling in the NAcc shell. We observed that cocaine self-administration reduces synaptically evoked excitatory responses recorded extracellularly in the NAcc shell compared to saline self-administration. This alteration was not accompanied by alterations in paired pulse ratio of synaptically evoked responses or in potentiation of these responses by application of the adenylyl cyclase activator forskolin. This reduction in glutamatergic signaling may be one mechanism by which cocaine exerts its long-term behavioral effects.

Neuropsychopharmacology (2006) 3 I, |444-|45I. doi:I0.I038/sj.npp. I3009 I8; published online 5 October 2005
\end{abstract}

Keywords: nucleus accumbens shell; cocaine; self-administration; glutamate; synaptic transmission

\section{INTRODUCTION}

Accumulating evidence suggests that a common feature of many drugs of abuse is that they produce alterations in excitatory signaling, both directly through the regulation of synaptic function (Lu et al, 1997, 1999; Lu and Wolf, 1999; Hyman and Malenka, 2001; Winder et al, 2002; Lovinger et al, 2003), and indirectly through the regulation of cellular excitability (Zhang et al, 2002; Hu et al, 2004, 2005) in reward circuitry. Evidence to date suggests that psychostimulants differentially regulate glutamatergic synaptic transmission in the ventral tegmental area (VTA) and the nucleus accumbens (NAcc), two key components of the reward circuitry. Chronic intraperitoneal (i.p.) administration of cocaine increases strength at excitatory synapses onto midbrain dopamine neurons in the VTA (Borgland

\footnotetext{
*Correspondence: Dr DG Winder, Department of Molecular Physiology and Biophysics, Vanderbilt University School of Medicine, 724B Robinson Research Building, 23rd and Pierce Ave., Nashville, TN 37232-06/5, USA, Tel: + | 615322 ||44, Fax: + | 615 322 1462; E-mail: danny.winder@vanderbilt.edu

${ }^{4}$ Current address: Department of Pharmacology and Cancer Biology, Duke University, Room I00B Research Park Bldg 2, PO Box 3813, Durham, NC 277I0, USA.

Received 3 March 2005; revised 12 August 2005; accepted 30 August 2005

Online publication: I September 2005 at http://www.acnp.org/citations/ Npp090 I05050 I48/default.pdf
}

et al, 2004), while reducing excitatory synaptic strength in the NAcc (Thomas et al, 2001).

While these studies have demonstrated clear mechanisms by which cocaine may regulate brain function, a major question left unanswered is whether contingent administration of cocaine produces the same alterations. It is well-established that excitatory signaling plays a role in behaviors related to self-administration, in both acquisition (Suto et al, 2002) and reinstatement of drug seeking after extinction (Cornish et al, 1999; Cornish and Kalivas, 2000). In the cocaine self-administration model, mice learn the behaviors necessary to obtain the drug, as human drug users do. They also learn that the drug-seeking behaviors lead to a highly reinforcing result. This cognitive, learned aspect of self-administration may make it markedly different from i.p. administration. Furthermore, the route of delivery used for self-administration, intravenous infusion, achieves greater and faster brain levels of cocaine than i.p. administration. Indeed, rapid entry via this route into the brain may be very important for the development of addiction (Samaha et al, 2002, 2004; Samaha and Robinson, 2005). Finally, with self-administration, the mice choose their own frequency of intake, presumably to maintain the most reinforcing level of cocaine. All of these differences may affect the way that cocaine interacts with the drugreward circuitry.

We have therefore performed experiments to begin to determine whether alterations in excitatory signaling occur 
following self-administration of cocaine in a manner analogous to i.p. administration. We compared extracellularly recorded synaptically evoked glutamatergic responses in the NAcc shell from adult mice that had self-administered cocaine or saline. Consistent with observations from i.p. cocaine experiments, we have found that self-administered cocaine depresses synaptic responses in the NAcc compared to saline.

\section{METHODS}

\section{Self-Administration Methods}

Mice. All procedures were approved by Vanderbilt University's Institutional Animal Care and Use Committee. A total of 41 male, $\mathrm{C} 57 \mathrm{Bl} / 6 \mathrm{~J}$ mice at $5-6$ weeks of age were received from Jackson Laboratories (Bar Harbor, ME). They were allowed to acclimate for at least 1 week in the animal care facility before the start of training. Mice were identified by ear tagging (National Band and Tag).

Food deprivation. To aid in training for operant conditioning, mice were food-deprived. Food and water were taken away between 1500 and 1700 hours, and then returned between 0900 and 1100 hours the following day. They were allowed to eat and drink for $6 \mathrm{~h}$ per day with this regimen for 2 days. This procedure (for only 2 days) did not cause significant weight loss in the mice.

Food training. Food-deprived mice were trained in the MedAssociates operant chambers on an FR-1 schedule of reinforcement with 25\% Vanilla Ensure as the reinforcer and levers as the manipulanda, with one noncontingent reinforcer available at the start of the session. Sessions were $1 \mathrm{~h}$ each and were performed between 0900 and 1200 hours. Illumination of the house light indicated the start of the session, and cue lights indicated availability of the liquid reinforcer. Presses on the inactive lever were recorded but had no programmed consequences. Mice were trained in this way until they received 50 reinforcers for two consecutive sessions. This usually required 4-5 sessions. Mice that did not acquire 50 reinforcers within 12 training days were excluded from the rest of the study. Three mice were excluded for failing to learn to respond for food.

Self-administration training. Mice that successfully completed food training were catheterized in the right jugular vein with a silastic catheter. On the day of surgery, mice were anesthetized with Nembutal $(50 \mathrm{mg} / \mathrm{kg})$ injected intraperitoneally. After anesthetizing the mouse, the fur was removed from the intrascapula and the right and left side of the chest. The areas were then sterilized using a $10 \%$ povidone-iodine solution. A small longitudinal incision was made in the skin just over the anterior right jugular vein. The jugular vein was isolated from surrounding connective tissues. Two threads of 6-0 silk suture were passed under the vein with a separation of $\sim 3 \mathrm{~mm}$. The thread placed anteriorly was tied to prevent bleeding. A small incision was made in the vein just below the ligature and a silicone catheter filled with $20 \%$ heparin saline was inserted $11 \mathrm{~mm}$ into the lumen. The catheter was secured into place with the second thread and the previous thread used to prevent bleeding. The mouse was turned dorsal side up and a small incision was made on the intrascapula. A 14 gauge blunt needle was carefully inserted into the ventral incision and pushed subcutaneously until the end exited through the intrascapula incision. The catheter was carefully pulled through the needle. The ventral incision was closed using 7.0 prolene suture. The catheter was then connected to an access port. The port was made of hypo tube stainless steel tubing (HTX-25-12, Small Parts), Micro-Renethane tubing (Braintree Scientific), silicone tubing, and silicone. The bent portion of the access port was implanted subcutaneously on the intrascapula and the incision sutured with 4.0 and 7.0 prolene suture. The implanted catheter was then flushed with $20 \%$ heparinized saline. The total duration of the surgical procedure was $\sim 50 \mathrm{~min}$. Mice were individually placed on a postsurgical warming bed until fully awake. They were allowed to recover for 1-4 days with food and water available ad libidum before resuming self-administration training.

For self-administration training, the mice were food restricted: one pellet available per day, water available ad libitum. This method maintained the animals at approximately $90 \%$ of their free-feeding weight, and sufficiently motivated them to continue lever pressing for cocaine (Carroll et al, 1979, 1981). Self-administration was performed on an FR-1 schedule for 1 -h sessions with $0.3 \mathrm{mg} /$ $\mathrm{kg} /$ infusion as the training dose. Cue lights were illuminated during the 2.5-s infusion. Lever presses during the infusion were recorded but had no programmed consequences. As in food training, presses on the inactive lever were recorded but had no programmed consequences. Criteria for successful self-administration of cocaine were a modification of those published by Caine et al (2002): (1) stable daily responding (less than $20 \%$ variation across 2 consecutive days); (2) a minimum of 10 responses on the active lever; and (3) at least $70 \%$ of responses on the active lever. Mice that failed to meet these criteria were excluded from electrophysiological analysis. Two mice were excluded for this reason. Self-administration sessions were terminated if the mouse received 50 infusions. At the end of selfadministration training, catheter patency was verified with ketamine. Mice that lacked patent catheters were excluded from further analysis. In all, 14 mice were excluded for this reason.

Mice in the saline control group were treated exactly as the cocaine group, with the exception that they received saline via the intravenous catheters instead of cocaine. No saline mice were excluded based on the self-administration criteria or on the basis of blocked catheters; saline was not expected to act as a reinforcer. However, in some preliminary experiments, saline mice maintained stable lever pressing across several days and performed more than 10 lever presses per hour, which caused us to question whether the cocaine mice were truly seeking cocaine or merely lever pressing out of habit or failure to extinguish food responding. Therefore, we added an additional criterion for successful self-administration. After the 10th day of steady-state administration, mice were placed in the chambers with only saline available after each lever press. Mice receiving cocaine performed an extinction burst, or sharp increase in number of active lever presses. We took 
this as an indication of active drug seeking in the cocaine mice, because it was markedly absent in the saline mice. One mouse was excluded for failing to meet this criterion.

Dose-response determination in self-administration. For dose-response determination within each mouse, training began as described above with $0.3 \mathrm{mg} / \mathrm{kg} /$ infusion cocaine. When each mouse reached stable lever pressing behavior at this dose, meaning (1) he performed at least 10 presses on the active lever, (2) at least $70 \%$ of lever presses were on the active lever, and (3) there was less than $20 \%$ variation across two consecutive sessions (modification of criteria established by Caine et al, 2002), the dose was varied in pseudorandom order to 0.1 and $1 \mathrm{mg} / \mathrm{kg} /$ infusion. Administration of subsequent doses was performed until each mouse achieved stable lever pressing at that dose. (For these doses, criteria were (2) at least $70 \%$ of presses on the active lever and (3) less than $20 \%$ variation across two consecutive sessions.) The reported activity at each dose is the average number of active lever presses across the two days of stable lever pressing. After completion of the three doses within each mouse, saline replaced cocaine in the syringe for determination of extinction behavior.

Electrophysiology. Electrophysiologists were blinded to the drug history of the mice. Mice were anesthetized with isoflurane and decapitated. Brains were removed and placed in ice-cold ACSF for slicing (ACSF, in mM: NaCl, 124; $\mathrm{KCl}, 4.4 ; \mathrm{MgSO}_{4}, 1.2 ; \mathrm{NaH}_{2} \mathrm{PO}_{4}, 1 ; \mathrm{CaCl}_{2}, 2.5 ; \mathrm{NaHCO}_{3}, 26$; glucose, 10) as previously described (Schramm et al, 2002). Coronal slices (300-350 $\mu \mathrm{m}$ thick) containing the NAcc shell were allowed to recover for at least $1 \mathrm{~h}$ before recording. Analysis was performed on an interface chamber (Fine Science Tools) with ACSF plus $0.1 \%$ DMSO at $28-29^{\circ} \mathrm{C}$ at a flow rate of $1.5-2 \mathrm{ml} / \mathrm{min}$. The chamber was humidified and oxygenated with $95 \%$ oxygen $/ 5 \% \mathrm{CO}_{2}$. Recordings were made via borosilicate glass recording electrodes $(\sim 1 \mathrm{M} \Omega)$ filled with ACSF/DMSO (0.1\%) and placed in the NAcc shell. Stimuli were delivered via a Grass S88 stimulator. The stimulating electrode was also placed in the NAcc shell, about $500 \mu \mathrm{m}$ from the recording electrode. pCLAMP 8.0 and 9.0 software was used for data acquisition and analysis. An input-output curve was performed, in which the stimulator was set at 5, 10, 15, and $25 \mathrm{~V}$. The N1 (axonal, presynaptic) and $\mathrm{N} 2$ (glutamate-dependent, postsynaptic) responses were recorded at each voltage. The $\mathrm{N} 2 / \mathrm{N} 1$ ratio was calculated for each slice at each voltage in triplicate. Triplicates were averaged within each slice, then the ratios for multiple slices from a single mouse were averaged before inclusion in the group average. Stimuli that elicited approximately $1 / 2$ the maximal response were then used for paired-pulse analysis. Stimuli were delivered 20, 50, 80, $110,140,170$, and $200 \mathrm{~ms}$ apart and the ratio of the second to first peak was determined. The second to first peak ratios at each interstimulus interval from slices from the same animal were averaged before inclusion in the group average.

Following paired pulse ratio determination, half-maximal stimuli were delivered every $20 \mathrm{~s}$ for establishment of a baseline and for testing the effect of bath-applied forskolin. A minimum of $20 \mathrm{~min}$ of stable baseline recording was obtained before application of forskolin. Forskolin
$(10 \mu \mathrm{M})$ was applied for $15 \mathrm{~min}$. The percentage of baseline after forskolin application was determined for each slice, and percentage stimulations were averaged from slices from the same mouse before inclusion in the group average.

Statistical analysis was performed using Microsoft Excel and Statview and JMP 5.1 statistical software.

\section{RESULTS}

\section{Cocaine Self-Administration}

A within-subjects dose-response curve was generated and is shown in Figure 1. Mice were initially trained on an FR-1 schedule in 1 -h daily sessions at $0.3 \mathrm{mg} / \mathrm{kg} /$ infusion. They were then switched to 0.1 and $1.0 \mathrm{mg} / \mathrm{kg} /$ infusion in pseudorandom order. These three doses revealed the descending arm of the dose-response curve, similar to published reports with mice (Deroche et al, 1997; Caine et al, 2002). After all three doses were completed within each animal, a single extinction test was performed, in which all animals exhibited extinction burst behavior.

As shown in Figure 2, a second group of mice stably selfadministered cocaine on an FR-1 schedule for 10 daily 1-h sessions. Stable lever pressing was achieved in the cocaine group after 2-3 days of self-administration training and persisted in the mice that were ultimately used for electrophysiological analysis through the 10th day. Mice receiving cocaine that did not have patent catheters were excluded from further analysis (14 total). In the saline group, lever pressing progressively decreased over the first few days, down to a low basal rate.

Because of the slow extinction of lever pressing in the saline group, and because some members of the saline group maintained stable lever pressing behavior, we added an additional criterion to determine whether the mice in the cocaine group were seeking cocaine. We incorporated an extinction test, performed on the 11th day, in which both groups were given saline. All but one mouse from the cocaine group exhibited an extinction 'burst', or at least a $15 \%$ increase in lever pressing relative to the average number performed in the last 2 days of cocaine delivery.

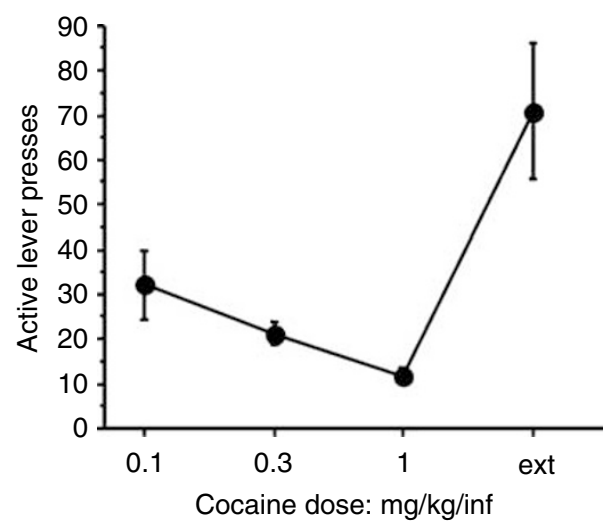

Figure I Within-subject cocaine dose-response relationship in selfadministration. Mice were trained initially at $0.3 \mathrm{mg} / \mathrm{kg} /$ infusion, as described in Methods, then switched to 0.1 and $1.0 \mathrm{mg} / \mathrm{kg} /$ infusion in pseudorandom order. $N=7$ mice; dose effect, $p<0.0001$ 
Time Line of self-administration to slicing experiments:

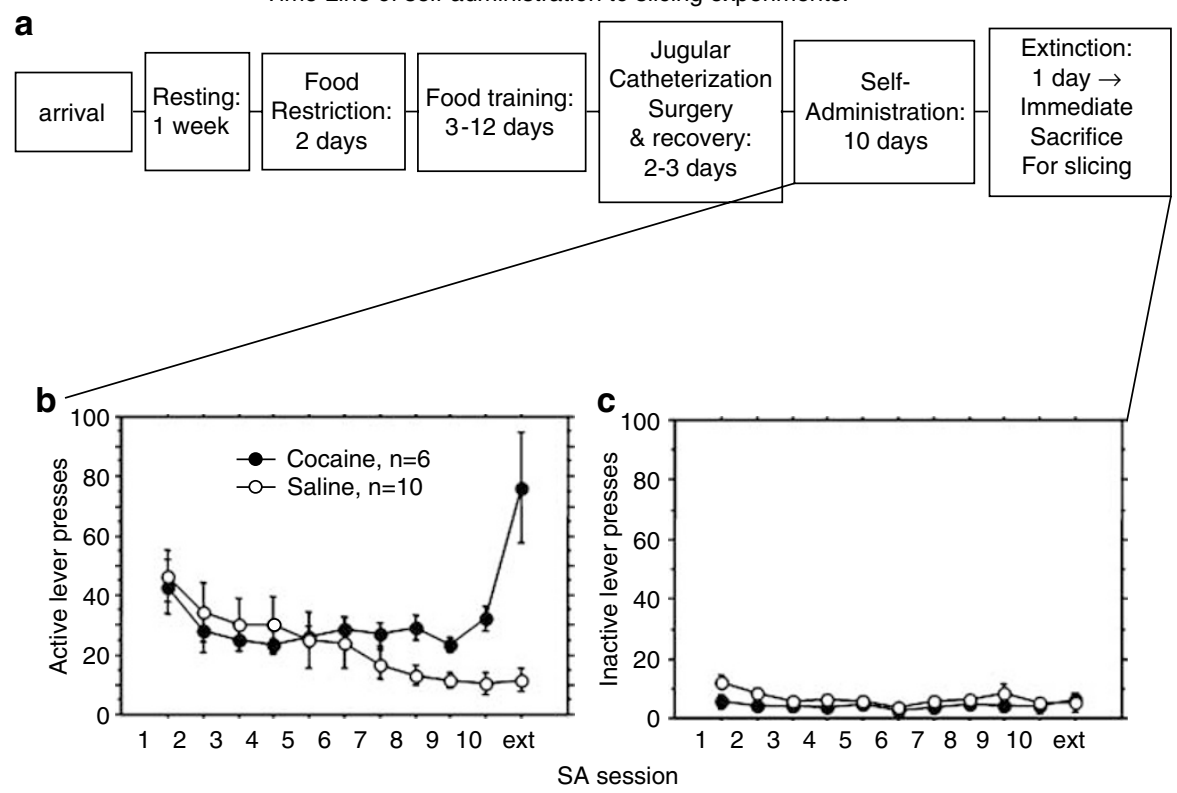

Figure 2 Self-administration in mice that were used for slicing experiments. (a) Time line of behavioral training and slicing experiments. (b) Active lever pressing in mice that were used for slice experiments. (c) Inactive lever pressing in mice that were used for slicing experiments. Cocaine, $N=6$ mice; saline, $N=10$ mice.

The one mouse that did not exhibit an extinction burst was excluded from further analysis.

\section{Analysis of Glutamatergic Responses}

After recovery from dissection, stimulating and recording electrodes were positioned within the shell of the NAcc, and extracellular field potentials were recorded in response to a range of stimulus intensities $(5-25 \mathrm{~V}$ for $50 \mu \mathrm{s})$. Electrical stimulation yielded a stereotypical response consisting of a stimulus artefact followed by two negative-going peaks (Figure 3a), which have been referred to as N1 and N2 (Takagi and Yamamoto, 1978; Cordingley and Weight, 1986). The N1 reflects in part the recruitment of presynaptic fibers, as it is blocked by tetrodotoxin, while the N2 response is a depolarization initiated by glutamatergic synaptic transmission (Cordingley and Weight, 1986). To compare glutamatergic responses from mice administering cocaine $v s$ saline, we compared the amplitudes of the $\mathrm{N} 2$ responses relative to $\mathrm{N} 1$ amplitudes across the two populations. Figure $3 \mathrm{~b}$ shows the $\mathrm{N} 2 / \mathrm{N} 1$ ratio from slices from mice exposed to cocaine or saline at stimulus intensities of 10,15 , and $25 \mathrm{~V}$. Ratio results obtained at $5 \mathrm{~V}$ showed extreme variability due to the small peak size at that voltage and were therefore excluded from presentation. Values from multiple slices from a single mouse were averaged before inclusion in the group average. There is a main effect of drug treatment: $\mathrm{N} 2 / \mathrm{N} 1$ ratios are smaller in slices from cocaine self-administering mice than from saline self-administering mice (RMANOVA, $p=0.0035$ ). By pairwise comparison, this effect is significant at the $15-\mathrm{V}$ stimulus intensity ( $t$-test, $p<0.05)$.

An alteration in the $\mathrm{N} 2 / \mathrm{N} 1$ ratio could be the product of upregulation of the $\mathrm{N} 1$, downregulation of the $\mathrm{N} 2$, or a combination of these two. To more specifically address changes in the N2 amplitude, we performed a linearregression analysis of the data set (Figure 3c). In this way, we could examine the variation in $\mathrm{N} 2$ response as a function of $\mathrm{N} 1$ response and of drug treatment. This analysis demonstrates that for every increase in N1, there is less of an increase in $\mathrm{N} 2$ in the cocaine-exposed slices than in the saline-exposed slices. The slopes of the relationship between $\mathrm{N} 1$ and N2 are significantly different between the cocaine and saline groups (by ANCOVA, the $\mathrm{N} 1$ by drug interaction term is significant with respect to $\mathrm{N} 2(p=0.0006))$.

\section{Mechanisms of Regulation of Glutamatergic Responses in Cocaine Self-Administering Mice}

A reduction in the amplitude of the synaptically evoked excitatory response could occur through multiple pre- or post-synaptic mechanisms. To begin to determine underlying mechanisms, we analyzed paired-pulse ratios of synaptically evoked responses in slices from the cocaine and saline self-administering animals. As shown in Figure $4 \mathrm{a}$, we found no difference in paired pulse ratios at the $1 / 2$ maximal stimulus intensity across a range of interstimulus intervals between cocaine- and saline-administering mice. Slices from both groups of animals exhibited facilitation of the second pulse relative to the first at short interstimulus intervals, which diminished with increasing interstimulus intervals. These data suggest that presynaptic release properties are unchanged between these two conditions.

One well-established response to cocaine administration is the upregulation of the cAMP signaling system (Self et al, 1998). To test whether this occurred in our mice and had functional consequences, we tested the response of slices from our mice to a cAMP-stimulating agent, forskolin. Previous studies have demonstrated that activation of 
a
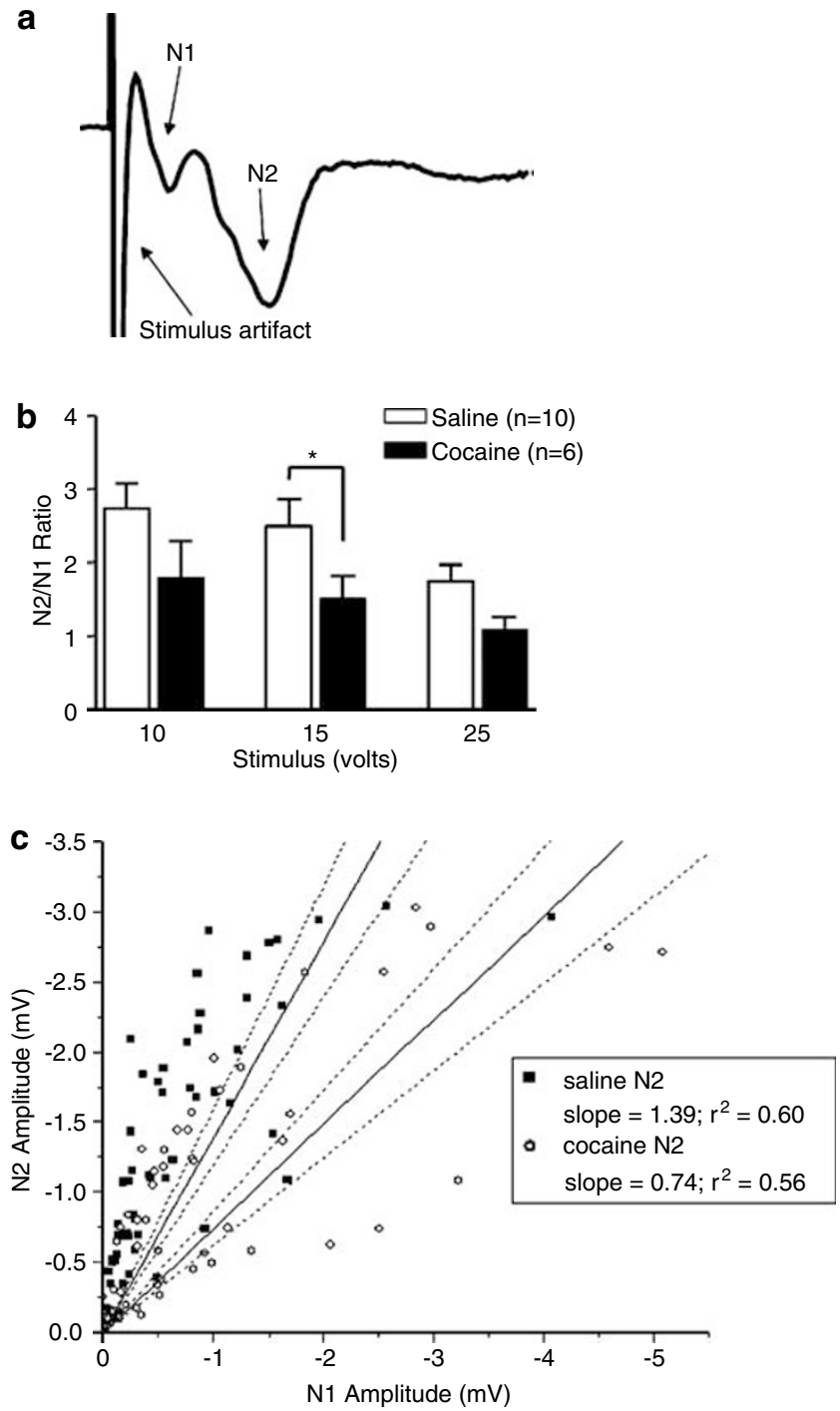

Figure 3 Electrophysiological data from the nucleus accumbens of mice after I day of extinction from self-administration. (a) Typical NAcc field response. Stimulus artefact, $\mathrm{NI}$ and $\mathrm{N} 2$ deflections are indicated. (b) N2/ $\mathrm{NI}$ ratios at stimulus intensities indicated. $N=6$ cocaine mice, $N=10$ saline mice. $* p<0.05$ by paired $t$-test. (c) Scatterplot and linear regression relating $N 1$ to $N 2$ (saline $N=64$ points from 16 slices from 10 mice, cocaine $N=40$ points from 10 slices from six mice).

adenylyl cyclase by forskolin markedly facilitates glutamatergic transmission in the NAcc (Schramm et al, 2002) through predominantly presynaptic mechanisms (Manzoni et al, 1998; Brundege and Williams, 2002). Therefore, we predicted that cAMP systems would be upregulated and therefore would occlude further stimulation by forskolin. To test this, we bath applied forskolin to slices from saline $v s$ cocaine self-administering animals, and found that peak effects are unchanged in the cocaine self-administering mice. Forskolin potentiated $70 \pm 17 \%$ responses in slices from cocaine-administering mice, and $86 \pm 28 \%$ in slices from saline-administering mice (mean \pm SEM). In total, these data suggest that the depression of $\mathrm{N} 2$ responses is not likely through alterations in presynaptic function, and that, if cAMP responses are altered in these slices, it does not affect the EPSPs that we measured.
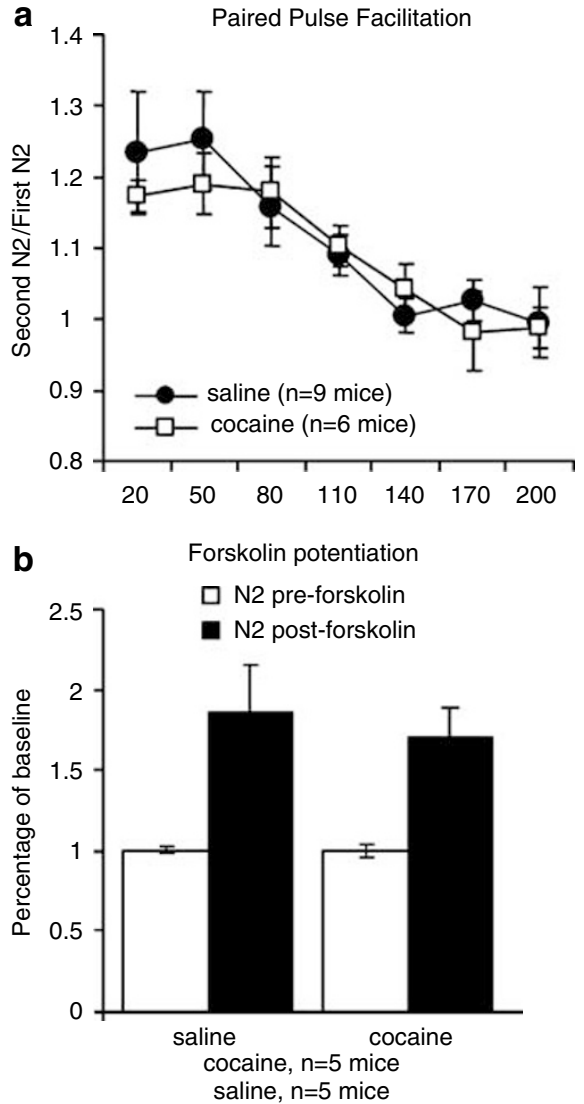

Figure 4 Analysis of paired pulse facilitation and forskolin-induced potentiation in slices from mice after self-administration. (a) Paired pulse facilitation, slices averaged from $N=9$ mice exposed to saline, and $N=6$ mice exposed to cocaine. (b) Forskolin-induced potentiation, $N=5$ mice exposed to cocaine; $N=5$ mice exposed to saline.

\section{DISCUSSION}

The importance of excitatory signaling pathways in responses to psychostimulants is well established. Psychostimulant administration alters both glutamatergic signaling and excitable properties of neurons, and pharmacologic agents that alter glutamatergic signaling can alter psychostimulant-related behaviors such as self-administration and locomotor sensitization (summarized below). In this study, we examined synaptically evoked excitatory responses in the NAcc shell from mice that had contingently administered cocaine and found that excitatory responses are depressed compared to those observed in saline-administering mice. This depression of excitatory responses likely represents an important change in the circuitry that mediates drug-seeking behavior.

\section{Alterations in NAcc Glutamate Receptor Subunit Expression by Psychostimulants}

Levels of the ionotropic glutamate receptor subunits of both the AMPA and NMDA subtypes are altered in the NAcc by psychostimulant administration. The changes are dependent upon the method of administration, brain region examined, and time after administration (withdrawal). After 5 days of i.p. psychostimulant administration followed by 14 
days of withdrawal, levels of the AMPA-type GluR1 subunit are reduced in the NAcc shell but not the core, while GluR2 subunit expression is reduced in both the NAcc core and shell ( $\mathrm{Lu}$ and Wolf, 1999). NMDA receptor expression in the $\mathrm{NAcc}$ is also altered by this drug-administration regimen. In the NAcc core and shell, NMDAR1 expression is reduced after 5 days of amphetamine administration followed by 14 days of withdrawal (Lu et al, 1999).

Glutamate receptor levels are also altered after cocaine self-administration in a region and time-sensitive manner. Perhaps most analogous to our experimental design, in the NAcc, GluR1, GluR2, and NMDA receptors are upregulated after 10 days of self-administration and 1 day of withdrawal. In the VTA, GluR2 and NMDA receptors are elevated, but not GluR1 receptors (Lu et al, 2003). This upregulation in the NAcc would seem to contradict our results. Reasons for this may lie in the control group used (food-trained in the Lu et al study, saline in our study), or in the specificity of the tissue punch, which contained both shell and core, and synaptic and extrasynaptic receptors, while we specifically recorded synaptic responses in the shell.

Interestingly, extinction of self-administration can also manipulate levels of AMPA-type receptors. After 1 week of extinction training, when drug-seeking behavior is extinguished, GluR1 and GluR2/3 levels are upregulated in the NAcc relative to withdrawn animals (Sutton et al, 2003). Simulating this upregulation using viral expression of GluR1 or GluR2 accelerates the process of extinction (Sutton et al, 2003). These reports, combined with our results and the results of sensitization studies mentioned earlier, suggest that reduced levels of glutamatergic signaling are associated with elevated drug craving, while elevated levels of glutamate receptors are associated with reduced drug craving. In total, results obtained to date from analysis of receptor expression levels generate a complex picture. Continued analysis of functional synaptic responses, as in this and other studies, will be necessary to clarify how psychostimulant intake alters glutamatergic transmission.

\section{Alterations in Glutamate Release by Psychostimulants}

In addition to the postsynaptic receptors mediating the fast synaptic actions of glutamate, evidence suggests that glutamate dynamics are also altered by psychostimulants. Extrasynaptic glutamate levels are altered by cocaine selfadministration. In animals trained to self-administer and then subjected to extinction training, extracellular glutamate levels in the NAcc are reduced at baseline (McFarland et al, 2003). Then, upon cocaine challenge, extracellular glutamate sharply increases (McFarland et al, 2003). At present, it is difficult to compare directly our findings that measure the effects of synaptically released glutamate, to these microdialysis studies that are thought to sample primarily extrasynaptic glutamate (Baker et al, 2002).

\section{Alterations in Excitatory Signaling and Behavioral Responses to Psychostimulants}

A growing body of literature indicates that psychostimulants produce complex alterations in excitatory signaling systems, as assayed both biochemically and electrophysiologically. Consistent with these alterations, behavioral pharmacological experiments as well as genetic manipulations highlight the importance of excitatory signaling in responses to psychostimulants. For example, during the maintenance phase of self-administration, stimulation of either AMPA or NMDA-type glutamate receptors enhances the reinforcing efficacy of cocaine (Cornish et al, 1999). After extinction, agonism of AMPA receptors in the NAcc induces reinstatement of drug seeking. Conversely, blockade of AMPA, but not NMDA or dopaminergic receptors in the NAcc inhibits cocaine-induced reinstatement of drug seeking in self-administration (Cornish and Kalivas, 2000). Stimulation of AMPA receptors in the NAcc can induce reinstatement of drug seeking after extinction. Further, in addition to the ionotropic glutamate receptors, the metabotropic glutamate receptors (mGluRs) also function in behaviors related to psychostimulants (Kim and Vezina, 1998a, b; Suto et al, 2003; Kim et al, 2005).

The NAcc is a site of integration of emotional and motivational stimuli which influences motor output. It receives glutamatergic inputs from the prefrontal cortex, hippocampus, and amygdala and receives dopaminergic input from the VTA. Its main outputs are medium spiny GABAergic neurons that send projections to areas involved in motor output including pallidum, midbrain, substantia nigra, and VTA (summarized in Mulder et al, 1998). In our study, we found reductions in glutamatergic synaptic strength onto the medium spiny GABAergic neurons that constitute over $90 \%$ of NAcc neurons (Zhou et al, 2002). These alterations could result from a complex array of changes in the inputs to the region. For example, several reports have shown that cocaine and other drugs of abuse strengthen glutamatergic signaling in the VTA (Ungless et al, 2001; Saal et al, 2003; Borgland et al, 2004), which may enhance inhibitory dopamine signaling in the NAcc as a result. Furthermore, the changes we observed would most likely reduce GABAergic output from the NAcc, and would thereby reduce inhibitory signaling in motor output areas, and could thereby produce diverse behavioral alterations.

\section{Contingent and Noncontingent Psychostimulant Administration Produce Common Effects on Excitatory Responses in the NAcc Shell}

Previously, Thomas et al (2001) showed that sensitization to cocaine (5 days of i.p. administration) caused a reduction in the AMPA/NMDA ratio in the NAcc shell (but not the core) and occlusion of LTD in NAcc shell. These two observations indicate an overall reduction in the responsivity of cells in this region to glutamatergic inputs. Other research examining electrophysiological changes after experimenter-administered cocaine suggests additional molecular alterations that may also contribute to an overall dampening of excitatory responses in the NAcc. The function of multiple types of ion channels within cells of the NAcc is reduced, leading to a dampening of cell excitability: i.p. cocaine followed by 3 days of withdrawal leads to a suppression of high voltage-activated calcium potentials and an enhancement of potassium channel activity (Hu et al, 2004). N- and $\mathrm{R}$-type calcium channel activity is also reduced (Zhang et al, 2002). Sodium channel phosphorylation is enhanced $(\mathrm{Hu}$ et al, 2005), leading to a reduction in sodium channel activation (Zhang et al, 1998). These multiple alterations 
likely converge to regulate the net output from the NAcc after cocaine administration. Our results now demonstrate that, as with i.p. administration of cocaine, self-administered cocaine also produces a reduction in excitatory signaling in the NAcc shell. It is likely that many of the individual molecular alterations described above summate to produce the alterations we observed in the field EPSP.

The effects of dopaminergic inputs to the NAcc are also altered by i.p. administration. After 5 days of i.p. injection of cocaine followed by 10-14 days of withdrawal, the ability of dopamine to inhibit glutamatergic stimulation of NAcc neurons was enhanced relative to saline-treated controls (Beurrier and Malenka, 2002). In the VTA, a region which sends dopaminergic projections to the NAcc, a single i.p. injection of cocaine leads to an upregulation of the AMPA/ NMDA ratio and an occlusion of LTP on dopaminergic neurons (Ungless et al, 2001). These findings indicate enhanced responsiveness of dopaminergic neurons of the VTA. Thus, the NAcc experiences potentially increased dopaminergic input as well as increased inhibitory responsiveness to that input, resulting in the net dampening of the excitable signaling that we observed.

It was important to directly examine whether alterations elicited by experimenter-administered cocaine occur after self-administered cocaine, because there are two major differences between the two modes of administration. First is the contingent nature of the administration. Contingency has been shown to alter uniquely some responses to drugs of abuse. For example, extracellular glutamate levels in the NAcc are uniquely upregulated upon cocaine priming in self-administering but not yoked control animals (McFarland et al, 2003). In addition, the turnover of acetylcholine in several brain regions (Mark et al, 1999; Smith et al, 2004), CRF receptor gene expression in the hypothalamus (Crespo et al, 2003), and the noradrenergic regulation of metabotropic glutamate receptor mediated inhibition of dopamine neurons (Paladini et al, 2004) are all altered in a contingency-dependent manner.

We would have predicted that glutamatergic transmission in brain regions that are crucial for the learning and conditional reinforcement processes (ie contingency) associated with drug seeking, such as the NAcc shell would be altered by contingently delivered drug, while those regions that function in the unconditioned pharmacological responses to the drug would be altered regardless of the method of administration. Our results, however, show that self-administration of cocaine alters the responsivity of NAcc neurons to glutamatergic signaling in a way which is qualitatively similar to what happens after repeated i.p. administration. This may suggest that the NAcc is a brain region that is less sensitive to contingency or route of administration, or that other aspects of NAcc signaling are contingently regulated.

The second major way in which self-administration differs from i.p. administration is the route of administration, and thereby the rate at which the drug reaches the brain. The route of administration used for self-administration, intravenous infusion, achieves greater and faster brain levels of cocaine than i.p. administration. Rapid entry via this route into the brain appears to be very important for the development of addiction (Samaha et al, 2002; Samaha et al, 2004; Samaha and Robinson, 2005). Thus, it was important that we compare our results to those obtained after i.p. administration.

It will now be important to examine what happens in other regions of the drug-reward circuitry that might influence drug-seeking behavior. For instance, in the bed nucleus of the stria terminalis (BNST), excitatory synaptic transmission is enhanced after cocaine self-administration relative to i.p. administered cocaine, passive i.v. infusion of cocaine or saline, and food self-administration (Dumont et al, 2005). Other brain regions may be similarly sensitive.

\section{ACKNOWLEDGEMENTS}

We thank Carlo Malabanan, Jamie Yates, and Tasneem Ansari of the Mouse Metabolic Phenotyping Center for assistance with jugular catheterization surgeries, and David Self and the members of his lab for helpful advice. This work was supported by a NARSAD young investigator award, as well as NIDA support (DA14151 to NLSS; DA 19112 to DGW) and NIMH support (MH65215, CMO).

\section{REFERENCES}

Baker DA, Xi ZX, Shen H, Swanson CJ, Kalivas PW (2002). The origin and neuronal function of in vivo nonsynaptic glutamate. $J$ Neurosci 22: 9134-9141.

Beurrier C, Malenka RC (2002). Enhanced inhibition of synaptic transmission by dopamine in the nucleus accumbens during behavioral sensitization to cocaine. J Neurosci 22: 5817-5822.

Borgland SL, Malenka RC, Bonci A (2004). Acute and chronic cocaine-induced potentiation of synaptic strength in the ventral tegmental area: electrophysiological and behavioral correlates in individual rats. J Neurosci 24: 7482-7490.

Brundege JM, Williams JT (2002). Differential modulation of nucleus accumbens synapses. J Neurophysiol 88: 142-151.

Caine SB, Negus SS, Mello NK, Patel S, Bristow L, Kulagowski J et al (2002). Role of dopamine D2-like receptors in cocaine selfadministration: studies with D2 receptor mutant mice and novel D2 receptor antagonists. J Neurosci 22: 2977-2988.

Carroll ME, France CP, Meisch RA (1979). Food deprivation increases oral and intravenous drug intake in rats. Science 205: 319-321.

Carroll ME, France CP, Meisch RA (1981). Intravenous selfadministration of etonitazene, cocaine and phencyclidine in rats during food deprivation and satiation. J Pharmacol Exp Ther 217: 241-247.

Cordingley GE, Weight FF (1986). Non-cholinergic synaptic excitation in neostriatum: pharmacological evidence for mediation by a glutamate-like transmitter. Br J Pharmacol 88: 847-856.

Cornish JL, Duffy P, Kalivas PW (1999). A role for nucleus accumbens glutamate transmission in the relapse to cocaineseeking behavior. Neuroscience 93: 1359-1367.

Cornish JL, Kalivas PW (2000). Glutamate transmission in the nucleus accumbens mediates relapse in cocaine addiction. J Neurosci (Online) 20: RC89.

Crespo JA, Manzanares J, Oliva JM, Corchero J, Garcia-Lecumberri C, Ambrosio E (2003). Extinction of cocaine self-administration produces alterations in corticotropin releasing factor gene expression in the paraventricular nucleus of the hypothalamus. Brain Res Mol Brain Res 117: 160-167.

Deroche V, Caine SB, Heyser CJ, Polis I, Koob GF, Gold LH (1997). Differences in the liability to self-administer intravenous cocaine between C57BL/6 $\times$ SJL and BALB/cByJ mice. Pharmacol Biochem Behav 57: 429-440. 
Dumont EC, Mark GP, Mader S, Williams JT (2005). Selfadministration enhances excitatory synaptic transmission in the bed nucleus of the stria terminalis. Nat Neurosci 8: 413-414.

Hu XT, Basu S, White FJ (2004). Repeated cocaine administration suppresses HVA-Ca2+ potentials and enhances activity of $\mathrm{K}+$ channels in rat nucleus accumbens neurons. J Neurophysiol 92: 1597-1607.

Hu XT, Ford K, White FJ (2005). Repeated cocaine administration decreases calcineurin (PP2B) but enhances DARPP-32 modulation of sodium currents in rat nucleus accumbens neurons. Neuropsychopharmacology 30: 916-926.

Hyman SE, Malenka RC (2001). Addiction and the brain: the neurobiology of compulsion and its persistence. Nat Rev Neurosci 2: 695-703.

Kim JH, Austin JD, Tanabe L, Creekmore E, Vezina P (2005). Activation of group II mGlu receptors blocks the enhanced drug taking induced by previous exposure to amphetamine. Eur $J$ Neurosci 21: 295-300.

Kim JH, Vezina P (1998a). The metabotropic glutamate receptor antagonist (RS)-MCPG produces hyperlocomotion in amphetamine pre-exposed rats. Neuropharmacology 37: 189-197.

Kim JH, Vezina P (1998b). Metabotropic glutamate receptors are necessary for sensitization by amphetamine. Neuroreport 9: 403-406.

Lovinger DM, Partridge JG, Tang KC (2003). Plastic control of striatal glutamatergic transmission by ensemble actions of several neurotransmitters and targets for drugs of abuse. Ann NY Acad Sci 1003: 226-240.

Lu L, Grimm JW, Shaham Y, Hope BT (2003). Molecular neuroadaptations in the accumbens and ventral tegmental area during the first 90 days of forced abstinence from cocaine selfadministration in rats. J Neurochem 85: 1604-1613.

Lu W, Chen H, Xue CJ, Wolf ME (1997). Repeated amphetamine administration alters the expression of mRNA for AMPA receptor subunits in rat nucleus accumbens and prefrontal cortex. Synapse 26: 269-280.

Lu W, Monteggia LM, Wolf ME (1999). Withdrawal from repeated amphetamine administration reduces NMDAR1 expression in the rat substantia nigra, nucleus accumbens and medial prefrontal cortex. Eur J Neurosci 11: 3167-3177.

Lu W, Wolf ME (1999). Repeated amphetamine administration alters AMPA receptor subunit expression in rat nucleus accumbens and medial prefrontal cortex. Synapse 32: 119-131.

Manzoni O, Pujalte D, Williams J, Bockaert J (1998). Decreased presynaptic sensitivity to adenosine after cocaine withdrawal. $J$ Neurosci 18: 7996-8002.

Mark GP, Hajnal A, Kinney AE, Keys AS (1999). Self-administration of cocaine increases the release of acetylcholine to a greater extent than response-independent cocaine in the nucleus accumbens of rats. Psychopharmacology (Berlin) 143: 47-53.

McFarland K, Lapish CC, Kalivas PW (2003). Prefrontal glutamate release into the core of the nucleus accumbens mediates cocaineinduced reinstatement of drug-seeking behavior. J Neurosci 23: 3531-3537.

Mulder AB, Hodenpijl MG, Lopes da Silva FH (1998). Electrophysiology of the hippocampal and amygdaloid projections to the nucleus accumbens of the rat: convergence, segregation, and interaction of inputs. J Neurosci 18: 5095-5102.

Paladini CA, Mitchell JM, Williams JT, Mark GP (2004). Cocaine self-administration selectively decreases noradrenergic regula- tion of metabotropic glutamate receptor-mediated inhibition in dopamine neurons. J Neurosci 24: 5209-5215.

Saal D, Dong Y, Bonci A, Malenka RC (2003). Drugs of abuse and stress trigger a common synaptic adaptation in dopamine neurons. Neuron 37: 577-582.

Samaha AN, Li Y, Robinson TE (2002). The rate of intravenous cocaine administration determines susceptibility to sensitization. J Neurosci 22: 3244-3250.

Samaha AN, Mallet N, Ferguson SM, Gonon F, Robinson TE (2004). The rate of cocaine administration alters gene regulation and behavioral plasticity: implications for addiction. J Neurosci 24: 6362-6370.

Samaha AN, Robinson TE (2005). Why does the rapid delivery of drugs to the brain promote addiction? Trends Pharmacol Sci 26: $82-87$.

Schramm NL, Egli RE, Winder DG (2002). LTP in the mouse nucleus accumbens is developmentally regulated. Synapse 45: 213-219.

Self DW, Genova LM, Hope BT, Barnhart WJ, Spencer JJ, Nestler EJ (1998). Involvement of cAMP-dependent protein kinase in the nucleus accumbens in cocaine self-administration and relapse of cocaine-seeking behavior. J Neurosci 18: 1848-1859.

Smith JE, Vaughn TC, Co C (2004). Acetylcholine turnover rates in rat brain regions during cocaine self-administration. J Neurochem 88: 502-512.

Suto N, Austin JD, Tanabe LM, Kramer MK, Wright DA, Vezina P (2002). Previous exposure to VTA amphetamine enhances cocaine self-administration under a progressive ratio schedule in a D1 dopamine receptor dependent manner. Neuropsychopharmacology 27: 970-979.

Suto N, Tanabe LM, Austin JD, Creekmore E, Vezina P (2003). Previous exposure to VTA amphetamine enhances cocaine selfadministration under a progressive ratio schedule in an NMDA, AMPA/kainate, and metabotropic glutamate receptor-dependent manner. Neuropsychopharmacology 28: 629-639.

Sutton MA, Schmidt EF, Choi KH, Schad CA, Whisler K, Simmons $\mathrm{D}$ et al (2003). Extinction-induced upregulation in AMPA receptors reduces cocaine-seeking behaviour. Nature 421: 70-75.

Takagi M, Yamamoto C (1978). Suppressing action of cholinergic agents on synaptic transmissions in the corpus striatum of rats. Exp Neurol 62: 433-443.

Thomas MJ, Beurrier C, Bonci A, Malenka RC (2001). Longterm depression in the nucleus accumbens: a neural correlate of behavioral sensitization to cocaine. Nat Neurosci 4: 1217-1223.

Ungless MA, Whistler JL, Malenka RC, Bonci A (2001). Single cocaine exposure in vivo induces long-term potentiation in dopamine neurons. Nature 411: 583-587.

Winder DG, Egli RE, Schramm NL, Matthews RT (2002). Synaptic plasticity in drug reward circuitry. Curr Mol Med 2: 667-676.

Zhang XF, Cooper DC, White FJ (2002). Repeated cocaine treatment decreases whole-cell calcium current in rat nucleus accumbens neurons. J Pharmacol Exp Ther 301: 1119-1125.

Zhang XF, Hu XT, White FJ (1998). Whole-cell plasticity in cocaine withdrawal: reduced sodium currents in nucleus accumbens neurons. J Neurosci 18: 488-498.

Zhou FM, Wilson CJ, Dani JA (2002). Cholinergic interneuron characteristics and nicotinic properties in the striatum. $J$ Neurobiol 53: 590-605. 